\title{
Prognostic significance of elongator protein 3 expression in endometrioid adenocarcinoma
}

\author{
YI WANG $^{1}$, JUN-ICHIRO IKEDA ${ }^{1}$, NUR RAHADIANI $^{1}$, SUHANA MAMAT $^{1,3}$, YUTAKA UEDA $^{2}$, TIAN TIAN $^{1}$, \\ TAKAYUKI ENOMOTO ${ }^{2}$, TADASHI KIMURA ${ }^{2}$, KATSUYUKI AOZASA $^{1}$ and EIICHI MORII ${ }^{1}$ \\ Departments of ${ }^{1}$ Pathology and Obstetrics and ${ }^{2}$ Gynecology, Osaka University Graduate School of Medicine, \\ Suita 565-0871, Japan; ${ }^{3}$ Department of Basic Health Science, Kulliyyah of Allied Health Sciences, \\ International Islamic University Malaysia, 25200 Kuantan, Pahang, Malaysia
}

Received March 1, 2011; Accepted July 27, 2011

DOI: $10.3892 / \mathrm{ol} .2011 .428$

\begin{abstract}
Elongator protein 3 (ELP3), the catalytic subunit of the elongator complex of RNA polymerase II, is involved in various functions, including transcriptional elongation, chromatin modification and cytoskeletal regulation. In this study, ELP3 expression was immunohistochemically examined in normal uterus tissue and uterine endometrioid adenocarcinoma tissue. ELP3 was abundantly expressed in both the proliferative and secretory phases of the endometrial cycle. However, ELP3 expression levels varied among cases of endometrioid adenocarcinoma. In patients with endometrioid adenocarcinoma, a low ELP3 expression was correlated to a high T-factor $(\mathrm{p}=0.036)$, tumor stage $(\mathrm{p}=0.001)$, lymph node metastasis $(\mathrm{p}<0.001)$, resistance to chemotherapy $(\mathrm{p}=0.045)$, recurrence $(p=0.004)$ and poor prognosis $(p=0.003)$. Univariate and multivariate analyses revealed that a low ELP3 expression was an independent factor for poor prognosis. In conclusion, this is the first study to examine the clinical implications of ELP3 expression in cancer.
\end{abstract}

\section{Introduction}

Elongator protein 3 (ELP3), the catalytic subunit of the elongator complex of RNA polymerase II, is involved in transcriptional elongation $(1,2)$. Besides transcriptional elongation, ELP3 possesses various functions, including chromatin modification by acetylation of histones (2) and demethylation of paternal DNA in zygotes (3). ELP3 is required for cell cycle progression in the presence of DNA-damaging agents in yeast (4). However, the opposite effect was reported in humans; ELP3 overexpression causes cell cycle arrest in a human embryonic kidney cell line (5). ELP3 also acetylates

Correspondence to: Dr Eiichi Morii, Department of Pathology, Graduate School of Medicine, Osaka University, Yamada-oka 2-2, Suita, Osaka 565-0871, Japan

E-mail: morii@patho.med.osaka-u.ac.jp

Key words: elongator protein 3, endometrioid adenocarcinoma, prognosis actin or tubulin in the microtubules of neurons (6-9). ELP3 mutation results in the degeneration of motor neurons in humans, suggesting a role for ELP3 in the migration and differentiation of neurons (10). Although a number of functions of ELP3 are known, the role of ELP3 in cancers and its clinical implications have yet to be studied.

Endometrioid adenocarcinoma is the most common invasive malignancy of the female genital system $(11,12)$. Despite advances in the methods of detection and treatment, the prognosis of patients with endometrioid adenocarcinoma remains unfavorable. We examined the clinical implications of the expression of a number of markers, including CDCP1 and ALDH1, in endometrioid adenocarcinoma. ELP3 expression has not been studied in endometrial tissue of the uterus. In the present study, ELP3 expression was immunohistochemically examined in normal endometrium and clinical samples with endometrioid adenocarcinoma, and its clinical implications were evaluated.

\section{Materials and methods}

Patients and methods. One hundred patients who underwent surgery for endometrioid adenocarcinoma at Osaka University Hospital, Japan, during the period between January 1998 and January 2007 were examined. Clinicopathological findings of the patients are shown in Table I. Patient ages ranged from 22 to 75 years (median 54.7). Resected specimens were macroscopically examined to determine the location and size of the tumors. Normal endometrial tissue (6 cases in the proliferative and 4 in the secretory phase), collected from patients with functional bleeding, was included as a control. Histological specimens were fixed in $10 \%$ formalin and paraffin-embedded. Paraffin-embedded specimens were stored in a dark room in the Department of Pathology of Osaka University Hospital at room temperature, sectioned at 4- $\mu \mathrm{m}$ at the time of staining, and stained with H\&E and an immunoperoxidase procedure. The histological stage was determined according to the International Federation of Obstetricians and Gynecologists (FIGO) staging system (15). The patients were followed up with laboratory examinations, including routine peripheral blood cell counts at 1- to 6-month intervals, X-ray, computed tomographic scan and pelvic examination at 6- to 
Table I. Summary of characteristics of 100 patients with endometrioid adenocarcinoma.

\begin{tabular}{lr}
\hline Characteristics & No. of patients \\
\hline Tumor & \\
T1 & 72 \\
T2 & 8 \\
T3 & 20 \\
Stage & \\
I & 63 \\
II & 4 \\
III & 27 \\
IV & 6 \\
Histological grade & \\
1 & 40 \\
2 & 39 \\
3 & 21 \\
Lymph node metastasis & \\
Negative & 75 \\
Positive & 25 \\
MIB-1 labeling index (\%) & \\
$<20$ & 16 \\
$\geq 20$ & 84 \\
Response to chemotherapy & \\
Response & \\
No response & \\
Recurrence & 21 \\
Negative & 17 \\
Positive & \\
Survival & \\
Yes (with no recurrence) & \\
Yes (with recurrence) & 20 \\
No & \\
\hline & \\
\hline & \\
\hline
\end{tabular}

12-month intervals. The follow-up period for survivors ranged from 7 to 122 months (median 82). The study was approved by the ethics review board of the Graduate School of Medicine, Osaka University.

Immunohistochemistry for ELP3 and MIB-1. ELP3 expression was immunohistochemically examined with anti-ELP3 antibody (Sigma, St. Louis, MO, USA). The proliferative activity of cancer cells was examined with monoclonal antibody MIB-1 (Immunotech, Marseilles, France), thereby identifying the proliferation-associated antigen Ki-67. Following antigen retrieval using a Pascal pressurized heating chamber (Dako A/S, Glostrup, Denmark), the sections were incubated with anti-ELP3 and MIB-1, diluted at $\mathrm{x} 250$ and $\mathrm{x} 100$ magnification, respectively, and then treated with a ChemMate EnVision kit (Dako). DAB (Dako) was used as a chromogen. As the negative control, staining was carried out in the absence of the primary antibody. Positive staining of endometrioid glandular epithelium was used as a positive control. Scoring for ELP3 staining was performed independently by two pathologists (J.I. and E.M.) who examined the samples in a blinded manner with respect to the clinical information of the subjects. Tumor cells expressing ELP3 revealed clear staining in the cytoplasm (Fig. 1), and the staining intensities were comparable to those of normal epithelia. Cases with $<10 \%$ ELP3-positive cells among tumor cells were regarded as ELP3-low, those with $10-25 \%$ cells as ELP3-intermediate and those with $>25 \%$ cells as ELP3-high. The MIB-1 labeling index was defined as the percentage of stained nuclei per 1,000 cells.

Double staining of ELP3 with MIB-1. Double staining of ELP3 with MIB-1 was carried out using the EnVision G/2 Doublestain system (Dako) according to the manufacturer's instructions. Sections were initially incubated with anti-ELP3 antibody (1:250), colored with DAB and, subsequently, Ki-67 expression was detected by MIB-1 (1:100), colored with Permanent Red (Dako).

Statistical analysis. Statistical analyses were performed using StatView software (SAS Institute Inc., Cary, NC, USA). The Chi-square and Fisher's exact probability tests were used to analyze the correlation between ELP3 expression and clinicopathological factors in endometrioid adenocarcinoma. Overall survival (OS) was measured from the time of diagnosis. Disease-free survival (DFS) was measured from the time of diagnosis until recurrence of the disease. The Kaplan-Meier method was used to calculate the OS and DFS rate, and differences in survival curves were evaluated with the log-rank test. Cox's proportional hazard regression model was used in a stepwise manner to analyze the independent prognostic factors. $\mathrm{P} \leq 0.05$ was considered to be statistically significant.

\section{Results}

Immunohistochemical findings. ELP3 expression was examined in normal endometrium. A strong ELP3 expression was detected in the endometrial glands of all the examined tissues (proliferative and secretory phases, Fig. 1A and B). The expression of ELP3 was then examined in 100 samples of endometrioid adenocarcinoma tissue. Tumor cells revealed variable ELP3 expression levels. Of the 100 cases, 13\% were classified as ELP3-high, $56(56 \%)$ as ELP3-intermediate and the remaining 31 cases (31\%) as ELP3-low (Figs. 1C-E).

Double staining of ELP3 with MIB-1. To examine the proliferation status of ELP3-expressing cells, double staining of ELP3 was carried out with MIB-1. ELP3-expressing and MIB-1-stained cells were almost mutually exclusive; most of the ELP3-expressing cells were negative for MIB-1, whereas most MIB-1-positive cells revealed no ELP3 expression (Fig. 2).

Correlation of ELP3 expression with clinical variables. The correlation of ELP3 expression levels (ELP3-high, ELP3-intermediate and ELP3-low) with clinicopathological characteristics was evaluated (Table II). A low ELP3 expression was correlated with a high $\mathrm{T}$-factor $(\mathrm{p}=0.036)$, stage 

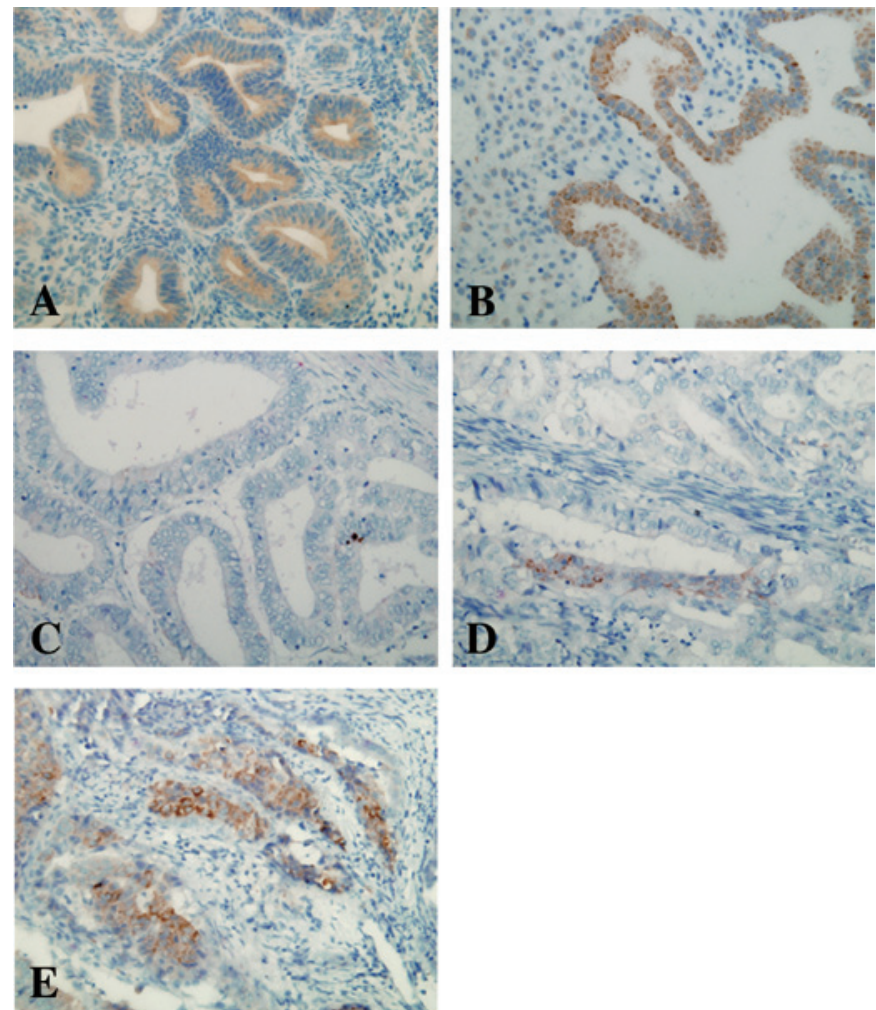

Figure 1. ELP3 expression in normal endometrium and endometrioid adenocarcinoma. Glandular epithelial cells in (A) normal proliferative and (B) secretory phase of endometrial epithelial cells expressed ELP3. Representative fields of (C) ELP3-low, (D) ELP3-intermediate and (E) ELP3high expression in endometrioid adenocarcinoma. Magnification, x200.

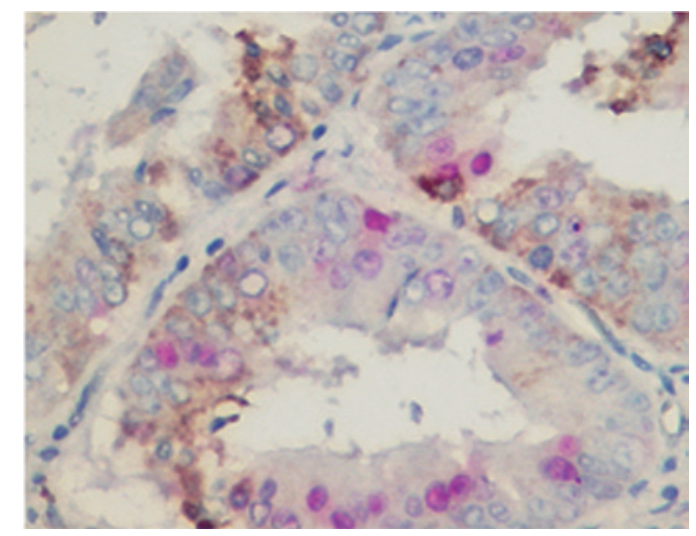

Figure 2. Double staining of ELP3 (brown color) and MIB-1 (red color) was performed. Magnification, x400.

$(\mathrm{p}=0.001)$, lymph node metastasis $(\mathrm{p}<0.001)$, resistance to chemotherapy $(\mathrm{p}=0.045)$, recurrence $(\mathrm{p}=0.004)$ and poor prognosis $(\mathrm{p}=0.003)$. Other parameters, including the histological grade of the tumor and the MIB-1 labeling index, did not correlate with ELP3 expression (Table II).

Five-year DFS and OS rates were 86.7 and $90.6 \%$, respectively. Tumors recurred in 21 patients. Of these, 15 patients succumbed to the disease. A statistically significant difference was found in DFS $(\mathrm{p}<0.001)$ and OS rates $(\mathrm{p}=0.001)$ among patients with ELP3-high, ELP3-intermediate and ELP3-low tumors (Fig. 3A and B).
Table II. Correlation between ELP3 expression and clinicopathological parameters.

\begin{tabular}{|c|c|c|c|c|}
\hline \multirow{3}{*}{ Tumor } & \multicolumn{3}{|c|}{ ELP3 expression } & \multirow[t]{2}{*}{ p-value } \\
\hline & Low & Intermediate & High & \\
\hline & & & & 0.036 \\
\hline $\mathrm{T} 1$ & 17 & 42 & 13 & \\
\hline $\mathrm{T} 2$ & 4 & 4 & 0 & \\
\hline T3 & 11 & 9 & 0 & \\
\hline Stage & & & & 0.001 \\
\hline I & 11 & 39 & 13 & \\
\hline II & 1 & 3 & 0 & \\
\hline III & 17 & 10 & 0 & \\
\hline IV & 2 & 4 & 0 & \\
\hline Histological grade & & & & 0.379 \\
\hline 1 & 10 & 24 & 6 & \\
\hline 2 & 11 & 22 & 6 & \\
\hline 3 & 10 & 10 & 1 & \\
\hline Lymph node metastasis & & & & $<0.001$ \\
\hline Negative & 15 & 47 & 13 & \\
\hline Positive & 17 & 8 & 0 & \\
\hline MIB-1 labeling index (\% & & & & 0.703 \\
\hline$<20$ & 4 & 9 & 3 & \\
\hline$\geq 20$ & 28 & 46 & 10 & \\
\hline $\begin{array}{l}\text { Response to } \\
\text { chemotherapy }\end{array}$ & & & & 0.045 \\
\hline Response & 7 & 11 & 3 & \\
\hline No response & 12 & 5 & 0 & \\
\hline Recurrence & & & & 0.004 \\
\hline Negative & 19 & 48 & 13 & \\
\hline Positive & 12 & 8 & 0 & \\
\hline Survival & & & & 0.003 \\
\hline $\begin{array}{l}\text { Yes (with no } \\
\text { recurrence) }\end{array}$ & 19 & 48 & 12 & \\
\hline $\begin{array}{l}\text { Yes (with } \\
\text { recurrence) }\end{array}$ & 1 & 5 & 0 & \\
\hline No & 11 & 3 & 1 & \\
\hline
\end{tabular}

Univariate analysis showed that the T-factor, stage, histological grade, lymph node metastasis and ELP3 expression were significant factors for both OS and DFS (Table III). The multivariate analysis revealed that ELP3 expression and histological grade were independent factors for OS. None of the factors were significant for DFS (Table III).

\section{Discussion}

In the present study, the characteristics of patients, such as age and tumor stage, were similar to those in a previous study by Steiner et al, indicating that our results are commonly applicable to endometrioid adenocarcinoma worldwide (16).

ELP3 expression was detected in non-cancerous endometrial glands of the proliferative and secretory phases. This is 

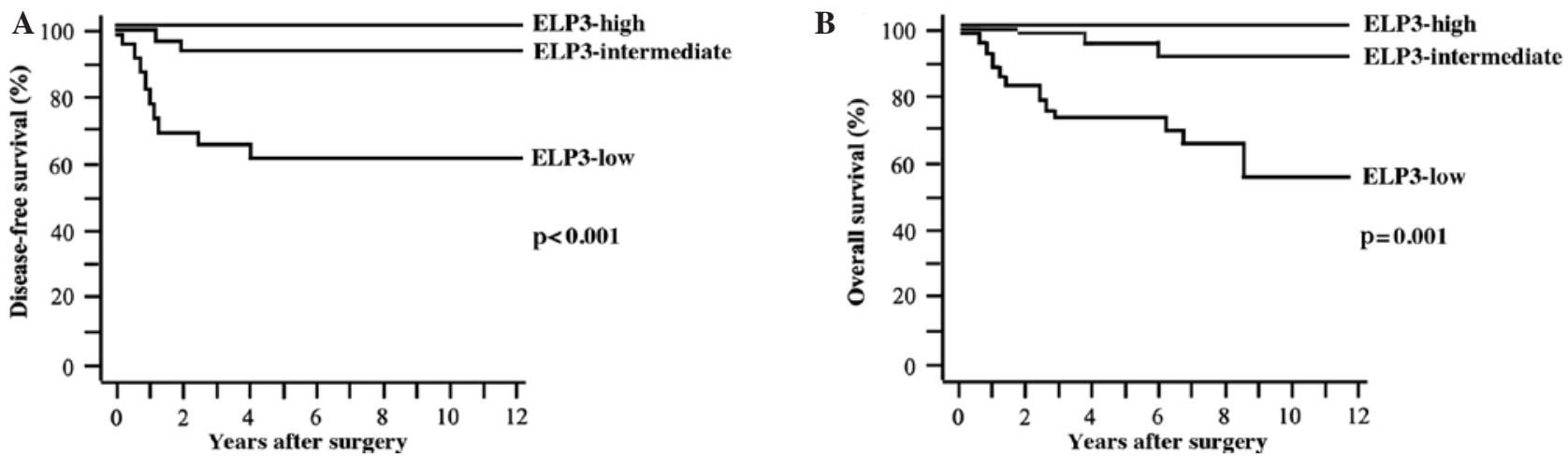

Figure 3. Kaplan-Meier plots. (A) Disease-free survival (DFS) and (B) overall survival (OS) curves are shown. ELP3-low cases showed less favorable DFS and OS.

Table III. Univariate and multivariate analyses of prognostic factors for overall survival (OS) and disease-free survival (DFS).

\begin{tabular}{|c|c|c|c|c|c|c|c|c|}
\hline & \multicolumn{4}{|c|}{ OS } & \multicolumn{4}{|c|}{ DFS } \\
\hline & \multicolumn{2}{|c|}{ Univariate } & \multicolumn{2}{|c|}{ Multivariate } & \multicolumn{2}{|c|}{ Univariate } & \multicolumn{2}{|c|}{ Multivariate } \\
\hline & $\begin{array}{c}\text { HR } \\
(95 \% \mathrm{CI})\end{array}$ & p-value & $\begin{array}{c}\text { HR } \\
(95 \% \mathrm{CI})\end{array}$ & p-value & $\begin{array}{c}\text { HR } \\
(95 \% \mathrm{CI})\end{array}$ & p-value & $\begin{array}{c}\mathrm{HR} \\
(95 \% \mathrm{CI})\end{array}$ & $\mathrm{p}$-value \\
\hline Tumor & $\begin{array}{c}1.54 \\
(1.23-1.93)\end{array}$ & 0.002 & $\begin{array}{c}1.21 \\
(0.82-1.80)\end{array}$ & 0.337 & $\begin{array}{c}1.59 \\
(1.26-2.00)\end{array}$ & $<0.001$ & $\begin{array}{c}1.44 \\
(0.94-2.22)\end{array}$ & 0.094 \\
\hline Stage & $\begin{array}{c}2.60 \\
(1.62-4.17)\end{array}$ & $<0.001$ & $\begin{array}{c}0.79 \\
(0.27-2.30)\end{array}$ & 0.660 & $\begin{array}{c}2.63 \\
(1.63-4.25)\end{array}$ & $<0.001$ & $\begin{array}{c}0.57 \\
(0.18-1.77)\end{array}$ & 0.329 \\
\hline Histological grade & $\begin{array}{c}3.32 \\
(1.58-7.00)\end{array}$ & 0.002 & $\begin{array}{c}3.10 \\
(1.20-8.01)\end{array}$ & 0.020 & $\begin{array}{c}3.29 \\
(1.58-6.83)\end{array}$ & 0.002 & $\begin{array}{c}2.38 \\
(0.89-6.37)\end{array}$ & 0.084 \\
\hline Lymph node metastasis & $\begin{array}{c}8.34 \\
(2.75-25.3)\end{array}$ & 0.002 & $\begin{array}{c}2.47 \\
(0.60-10.1)\end{array}$ & 0.210 & $\begin{array}{c}7.83 \\
(2.61-23.5)\end{array}$ & $<0.001$ & $\begin{array}{c}2.45 \\
(0.55-10.9)\end{array}$ & 0.240 \\
\hline MIB-1 labeling index & $\begin{array}{c}2.56 \\
(0.34-19.5)\end{array}$ & 0.364 & & & $\begin{array}{c}2.85 \\
(0.38-21.7)\end{array}$ & 0.311 & & \\
\hline ELP3 expression & $\begin{array}{c}0.19 \\
(0.07-0.52)\end{array}$ & 0.001 & $\begin{array}{c}0.24 \\
(0.07-0.79)\end{array}$ & 0.019 & $\begin{array}{c}0.21 \\
(0.08-0.57)\end{array}$ & 0.002 & $\begin{array}{c}0.33 \\
(0.10-1.11)\end{array}$ & 0.073 \\
\hline
\end{tabular}

HR, hazard ratio; CI, confidence interval.

the first study showing ELP3 expression in the endometrium. Although the role of ELP3 in normal endometrium remains to be elucidated, ELP3 may function as a tumor-suppressor in endometrioid adenocarcinoma, since a reduced expression of ELP3 correlated with a poor prognosis for patients. Low ELP3 expression was correlated with a high T-factor, an advanced stage, the occurrence of lymph node metastasis, resistance to chemotherapy and a high recurrence rate. Recently, Gu et al reported that ELP3 overexpression inhibits cell growth and causes cell cycle arrest in a human embryonic kidney cell line (5). In the present study, ELP3-expressing cells stained negative with MIB-1, which is consistent with the findings of $\mathrm{Gu}$ et al.

Li et al reported that ELP3 is required for S-phase progression in yeast in the presence of DNA-damaging agents, such as hydroxyurea (4). By contrast, a high expression of ELP3 in humans was reported to correlate with vulnerability to anticancer drugs. This may be attributable to the difference in species. ELP3 is known to regulate the structure of chromatin and the methylation of genomes $(2,17)$. Although target genes epigenetically regulated by ELP3 have not yet been reported, the identification of target genes of ELP3 may aid in understanding the various effects ELP3 has on the human and yeast cell cycle.

In conclusion, a low ELP3 expression is a poor prognostic factor in endometrioid adenocarcinoma. Further studies are required to clarify whether ELP3 expression would be a useful prognostic marker in other types of cancer.

\section{Acknowledgements}

The authors thank Ms. Megumi Sugano, Ms. Etsuko Maeno and Ms. Takako Sawamura for their technical assistance. This study was supported by grants from the Ministry of Education, Culture, Sports, Science and Technology, Japan (no. 20590364 and no. 20014010). 


\section{References}

1. Wittschieben BO, Otero G, de Bizemont T, et al: A novel histone acetyltransferase is an integral subunit of elongating RNA polymerase II holoenzyme. Mol Cell 4: 123-128, 1999.

2. Hawkes NA, Otero G, Winkler GS, et al: Purification and characterization of the human elongator complex. J Biol Chem 277: 3047-3052, 2002.

3. Okada Y, Yamagata K, Hong K, Wakayama T and Zhang Y: A role for the elongator complex in zygotic paternal genome demethylation. Nature 463: 554-558, 2010.

4. Li Q, Fazly AM, Zhou H, Huang S, Zhang Z and Stillman B: The elongator complex interacts with PCNA and modulates transcriptional silencing and sensitivity to DNA damage agents. PLoS Genet 5: e1000684, 2009.

5. Gu J, Sun D, Zheng Q, Wang X, Yang H, Miao J, Jiang J and Wei W: Human elongator complex is involved in cell cycle and suppresses cell growth in 293T human embryonic kidney cells. Acta Biochim Biophys Sin 41: 831-838, 2009.

6. Solinger JA, Paolinelli R, Klöss H, et al: The Caenorhabditis elegans elongator complex regulates neuronal alpha-tubulin acetylation. PLoS Genet 6: e1000820, 2010.

7. Gardiner J, Barton D, Marc J and Overall R: Potential role of tubulin acetylation and microtubule-based protein trafficking in familial dysautonomia. Traffic 8: 1145-1149, 2007.

8. Barton D, Braet F, Marc J, Overall R and Gardiner J: ELP3 localises to mitochondria and actin-rich domains at edges of HeLa cells. Neurosci Lett 455: 60-64, 2009.
9. Creppe C, Malinouskaya L, Volvert ML, et al: Elongator controls the migration and differentiation of cortical neurons through acetylation of alpha-tubulin. Cell 136: 551-564, 2009.

10. Simpson CL, Lemmens R, Miskiewicz K, et al: Variants of the elongator protein 3 (ELP3) gene are associated with motor neuron degeneration. Hum Mol Genet 18: 472-481, 2009.

11. Jemal A, Siegel R, Ward E, Hao Y, Xu J and Thun MJ: Cancer Statistics. CA Cancer J Clin 59: 225-249, 2009.

12. Horn LC, Meinel A, Handzel R and Einenkel J: Histopathology of endometrial hyperplasia and endometrial carcinoma: an update. Ann Diagn Pathol 1: 297-311, 2007.

13. Mamat S, Ikeda J, Enomoto T, Ueda Y, Rahadiani N, Tian T, Wang Y, Qiu Y, Kimura T, Aozasa K and Morii E: Prognostic significance of CUB domain containing protein expression in endometrioid adenocarcinoma. Oncol Rep 23: 1221-1227, 2010.

14. Rahadiani N, Ikeda JI, Mamat S, et al: Expression of aldehyde dehydrogenase 1 (ALDH1) in endometrioid adenocarcinoma and its clinical implications. Cancer Sci 102: 903-908, 2011.

15. Zaino RJ: FIGO staging of endometrial adenocarcinoma: a critical review and proposal. Int J Gynecol Pathol 28: 1-9, 2009.

16. Steiner E, Eicher O, Sagemüller J, et al: Multivariate independent prognostic factors in endometrial carcinoma: a clinicopathologic study in 181 patients: 10 years experience at the Department of Obstetrics and Gynecology of the Mainz University. Int J Gynecol Cancer 13: 197-203, 2003.

17. Chinenov Y: A second catalytic domain in the Elp3 histone acetyltransferases: a candidate for histone demethylase activity? Trends Biochem Sci 27: 115-117, 2002. 